Supporting information

\title{
Enhanced biosurfactants production using developed fed-batch fermentation for effective heavy crude oil recovery
}

\author{
Nadia A. Samak ${ }^{1,3,4, \sharp}$, Tahany Mahmoud ${ }^{1,2, *^{*}}$, A. A. Aboulrous ${ }^{1}$, M. M. Abdelhamid ${ }^{1,2}$ Jianmin Xing $^{3,4^{*}}$ \\ ${ }^{1}$ Processes Design and Development Department, Petroleum Application Department \& Production \\ Department, Egyptian Petroleum Research Institute, Cairo, Egypt. \\ ${ }^{2}$ Enhanced oil recovery unit, Egyptian Petroleum Research Institute, Nasr City, Cairo 11727, Egypt \\ ${ }^{3}$ CAS Key Laboratory of Green Process and Engineering \& State Key Laboratory of Biochemical \\ Engineering, Institute of Process Engineering, Chinese Academy of Sciences, Beijing 100190, PR China. \\ ${ }^{4}$ College of Chemical Engineering, University of Chinese Academy of Sciences, 19 A Yuquan Road, \\ Beijing, 100049, PR China
}

$\ddagger$ These authors contributed equally to this work.

*Corresponding authors:

Tahany Mahmoud (tahany.mahmoud.a@gmail.com)

Jianmin Xing (jmxing@ipe.ac.cn) 

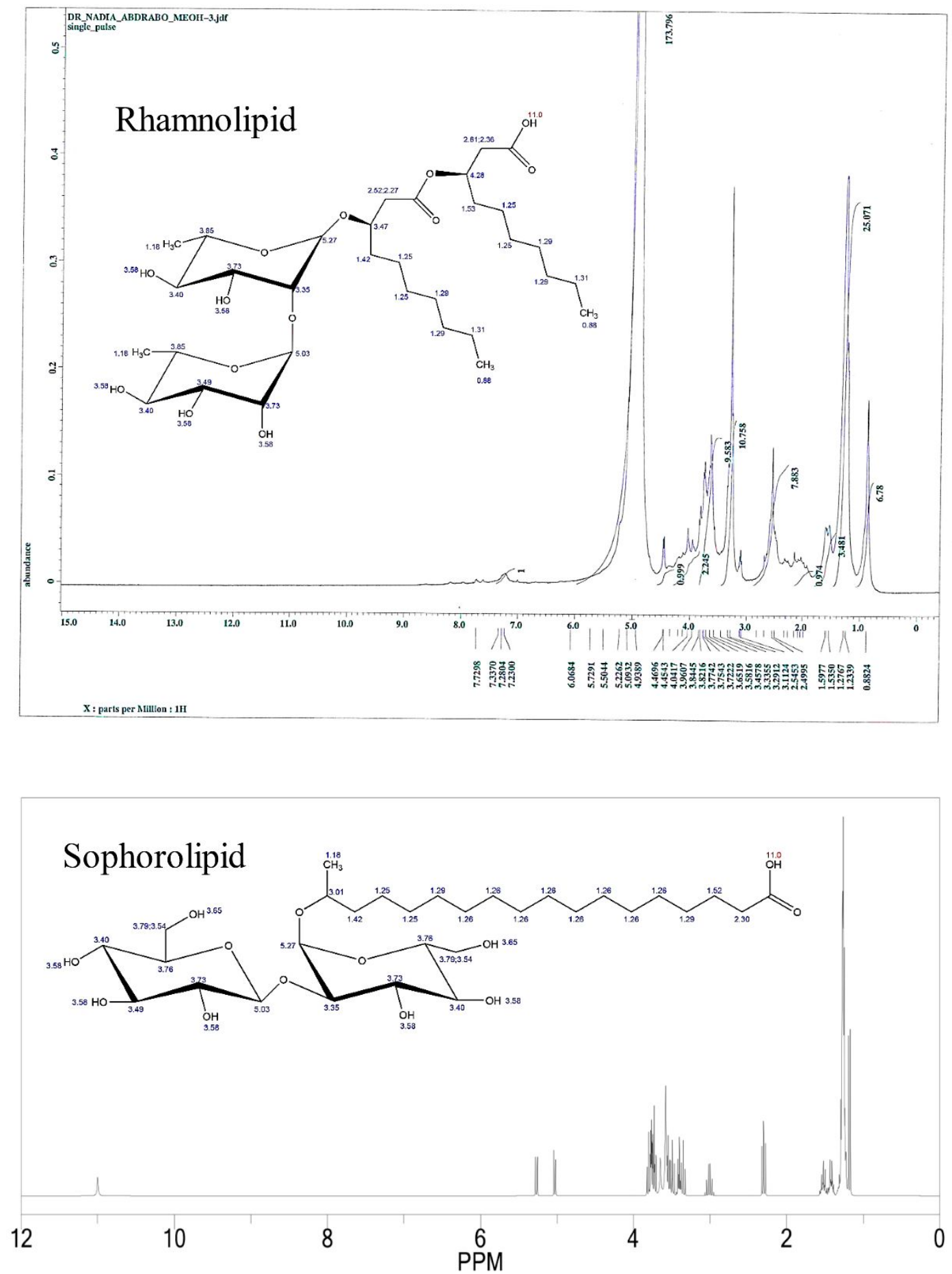

Figure S1. ${ }^{1} \mathrm{H}-\mathrm{NMR}$ spectra of rhamnolipid and sophorolipid produced by $P$. aeruginosa and $S$. bombicola, respectively 